\title{
ADSORPTION OF PHOSPHATE BY VARIOUS OXIDES: THEORETICAL TREATMENT OF THE ADSORPTION ENVELOPE
}

\author{
F. CABRERA, L. MADRID AND P. DE ARAMBARRI
}

(Centro de Edafologia y Biologia Aplicada del Cuarto, C.S.I.C., Apartado 1052, Sevilla, Spain)

\section{Summary}

An explanation is put forward for the shape of adsorption envelopes found for phosphate adsorption by various metallic oxides. The equation $x_{\mathrm{m}}=C_{1}\left(\mu_{\mathrm{H}_{3}} \mathrm{PO}_{4}+\right.$

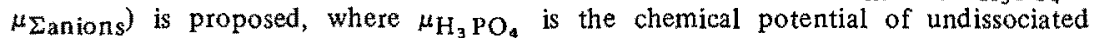
$\mathrm{H}_{3} \mathrm{PO}_{4} ; \mu_{\Sigma}$ anions is the chemical potential of all phosphate anions considered as one. component; $C_{\mathrm{g}}$ is a constant that includes influences of surface charge, chemical affinity of the metal for phosphate, specific surface area, etc $\mathrm{c}_{*}$ and $x_{\mathrm{m}}$ is the calculated Langmuir maximum adsorption of $\mathrm{p}$ at each $\mathrm{pH}$. The dependence of $C_{1}$ on the metal present in the oxide is shown.

\section{Introduction}

ANIONS that can be specifically adsorbed on certain mineral surfaces are held in amounts which are different at each $\mathrm{pH}$ value of the medium (Hingston et al., 1967). Most experimental data can be fitted to a Langmuir equation (Muljadi et al., 1966; Hingston et al., 1968, 1970, 1972; Obihara, 1969), which allows a maximum value for the adsorption to be calculated. Such values are related to $\mathrm{pH}$ by curves which have been termed 'adsorption envelopes'.

For phosphate, the adsorption envelope commonly shows breaks in the slope at $\mathrm{pH}$ values close to the second and third $\mathrm{pK}$ values of phosphoric acid. This shape has been recently interpreted by Bowden et al. (1973) using the Stern double-layer theory.

The main intention of the present paper is to suggest an explanation for the shape of the envelope for phosphate adsorption by different oxides based upon chemical potentials of species in solution. This explanation involves fewer parameters to be determined than the model proposed by Bowden et al. (1973).

\section{Materials and methods}

Gibbsite: a commerical sample supplied by Reynolds Metals Co., BET specific surface area $13.1 \mathrm{~m}^{2} \mathrm{~g}^{-1}$, and zero point of charge (ZPC) at $\mathrm{pH}$ 7.80 (method given by Herman and Boehm, 1969).

Boehmite: supplied by British Aluminium Co. ('Cera Hydrate'), BET specific surface area $2.9 \mathrm{~m}^{2} \mathrm{~g}^{-1}$, and ZPC at $\mathrm{pH} 7.24$.

Corundum: obtained by heating commercial aluminium oxide at 
$1200^{\circ} \mathrm{C}$ for $5 \mathrm{~h}, \mathrm{BET}$ specific surface area $6.0 \mathrm{~m}^{2} \mathrm{~g}^{-1}$, and $\mathrm{ZPC}$ at $\mathrm{pH}$ 3.55 .

Goethite: obtained from $\mathrm{Fe}\left(\mathrm{NO}_{3}\right)_{3} \cdot 9 \mathrm{H}_{2} \mathrm{O}$ by the method given by Taylor et al. (1964), BET specific surface area $87.4 \mathrm{~m}^{2} \mathrm{~g}^{-1}$, and ZPC at pH 8.45 .

Lepidocrocite: obtained from $\mathrm{FeCl}_{2} \cdot 4 \mathrm{H}_{2} \mathrm{O}$ by the method given by Brauer (1958), BET specific surface area $128.0 \mathrm{~m}^{2} \mathrm{~g}^{-1}$, and $\mathrm{ZPC}$ at $\mathrm{pH}$ 6.20.

Hematite I: obtained by precipitating $0.5 \mathrm{M}$ solution of $\mathrm{FeCl}_{3}$ at boiling point with $1: 1 \mathrm{NH}_{4} \mathrm{OH}$. After filtering and washing the amorphous solid, it was heated at $1000^{\circ} \mathrm{C}$ for $1 \mathrm{~h}$. BET specific surface area $1.2 \mathrm{~m}^{2} \mathrm{~g}^{-1}$, and $\mathrm{ZPC}$ at $\mathrm{pH} 6.45$.

Hematite II: obtained by heating $\mathrm{Fe}\left(\mathrm{NO}_{3}\right)_{3} .9 \mathrm{H}_{2} \mathrm{O}$ at $150^{\circ} \mathrm{C}$ for $1 \mathrm{~h}$, BET specific surface area $17.3 \mathrm{~m}^{2} \mathrm{~g}^{-1}$, and $\mathrm{ZPC}$ at $\mathrm{pH} 6.77$.

Pyrolusite: obtained by dissolving metallic $\mathrm{Mn}$ in $\mathrm{HNO}_{3}$ and subsequently evaporating the solution. The solid was washed with boiling conc. $\mathrm{HNO}_{3}$ in order to dissolve oxides of lower valency; BET specific surface area $2.3 \mathrm{~m}^{2} \mathrm{~g}^{-1}$, and $\mathrm{ZPC}$ at $\mathrm{pH} 5.63$.

Anatase: supplied by Bayer Hispania (Commmercial name Bayertitan AN-2), BET specific surface $13.8 \mathrm{~m}^{2} \mathrm{~g}^{-1}$, and ZPC at pH 7.54.

\section{Adsorption isotherms}

Suspensions of 0.2 to $1 \mathrm{~g}$ oxide in $50 \mathrm{ml}$ of $0.1 \mathrm{M} \mathrm{NaCl}$ solutions containing $\mathrm{KH}_{2} \mathrm{PO}_{4}$ with initial $\mathrm{P}$ concentrations ranging from 0 to 100 parts $10^{-6}$ were shaken at $25^{\circ} \mathrm{C}$ for $24 \mathrm{~h}$. Small quantities of $0.1 \mathrm{M}$ $\mathrm{NaOH}$ or $\mathrm{HCl}$ solutions were added to obtain the desired $\mathrm{pH}$. After shaking, $\mathrm{pH}$ was measured in the suspensions, and $\mathrm{P}$ concentration was measured in the clear supernatant solutions (Murphy and Riley, 1962). Adsorbed $\mathrm{P}$ was taken to be that lost from solution during shaking.

\section{Results and discussion}

Linear correlation coefficients between the equilibrium $P$ concentration and the quotient ( $\mathrm{P}$ concentration/adsorbed $\mathrm{P}$ ) for each adsorption isotherm were all highly significant $(\mathrm{P}<0.001$ for 65 isotherms and $\mathrm{P}<0.01$ for 23 , out of 95 isotherms determined), allowing Langmuir adsorption maxima $\left(x_{\mathrm{m}}\right)$ to be calculated. As an example, Fig. 1 shows experimental $x_{\mathrm{m}}$ values for goethite plotted against the corresponding $\mathrm{pH}$ values. The dashed line will be referred to later. The corresponding graphs for the other oxides studied are similar and are not presented here.

\section{Theoretical considerations}

According to Hingston et al. $(1970,1972)$ the mechanism of specific adsorption of anions on oxides implies the exchange of $\mathrm{H}_{2} \mathrm{O}$ molecules on the surface of the oxides for the dissociated anion. As the species on the surface of the oxides, $\mathrm{OH}^{-}$and/or $\mathrm{H}_{2} \mathrm{O}$, depend on the $\mathrm{ZPC}$ (zero 


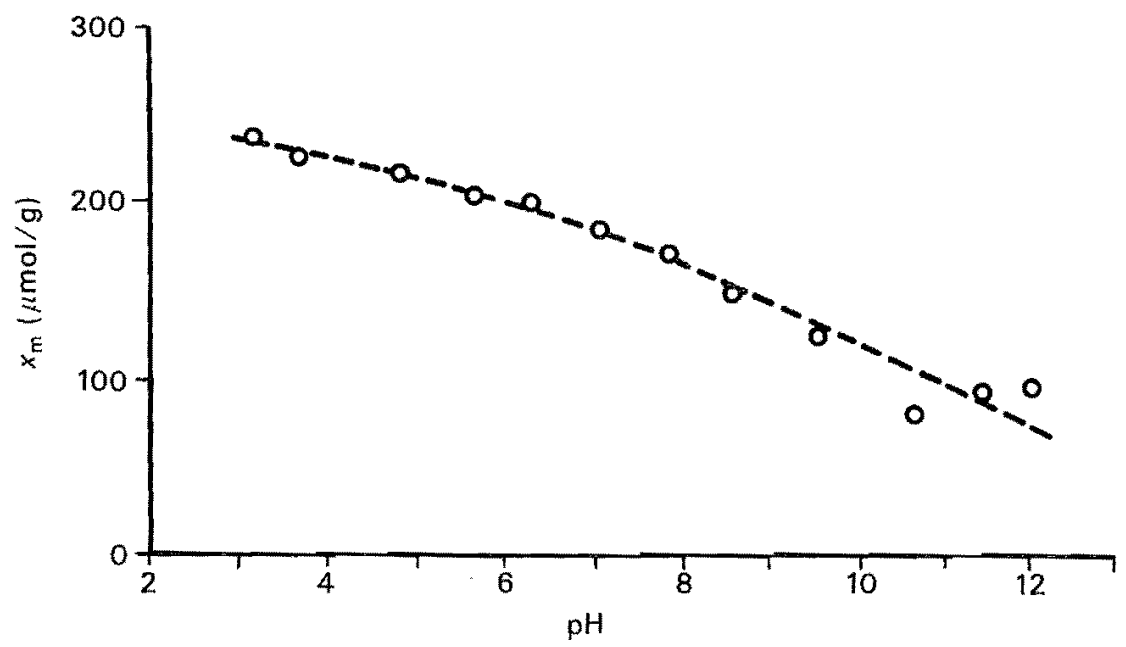

FIG. 1. Typical relationship (goethite) between experimental adsorption maxima and $\mathrm{pH}$ values of adsorption, with theoretical curve calculated using equation (8).

point of charge), the specific adsorption at $\mathrm{pH}$ higher than ZPC is only possible if the undissociated acid gives a proton to the $\mathrm{OH}^{-}$group on the surface to form $\mathrm{H}_{2} \mathrm{O}$, which is readily displaced by the anion.

For monoprotic acids the maximum amount of anion adsorbed, $x_{\mathrm{m}}$, at any $\mathrm{pH}$ is given by the expression

$$
x_{\mathrm{m}}=\frac{\Delta G}{R T} \alpha(1-\alpha)
$$

where $\Delta G$ is the maximum free energy of adsorption of the anion and $\alpha$ is the degree of dissociation.

This expression gives a maximum at $\mathrm{pH}=\mathrm{p} K_{\mathrm{a}}$, when $\alpha=0.5$. If such a maximum is identified with the experimental value, $V_{\mathrm{m}}$, of maximum $x_{\mathrm{m}}$, it can be written

$$
x_{\mathrm{m}}=4 V_{\mathrm{m}} \alpha(1-\alpha) \text {. }
$$

However, this function produces a curve which clearly falls below the experimental envelope (Hingston et al, 1970), and the authors believe that this arises from the assumption that $\Delta G$ is constant and independent of $\mathrm{pH}$.

According to Hingston et al. (1972), a similar treatment can only be applied to polyprotic acids (e.g. phosphoric acid) if the $\mathrm{p} K_{\mathrm{a}}$ values are sufficiently far apart, so that the effect of simultaneous existence of different proton donor species is avoided.

Nevertheless, if it is supposed that $\mathrm{H}_{3} \mathrm{PO}_{4}$ is the only species able to provide protons to the surface, a value of $(1-\alpha)$ can be defined as 


$$
(1-\alpha)=\frac{1}{1+\frac{K_{1}}{\left[\mathrm{H}^{+}\right]}+\frac{K_{1} K_{2}}{\left[\mathrm{H}^{+}\right]^{2}}+\frac{K_{1} K_{2} K_{3}}{\left[\mathrm{H}^{+}\right]^{3}}}
$$

where $K_{1}, K_{2}$, and $K_{3}$ are dissociation constants for phosphoric acid. Then

$$
\alpha=\frac{\frac{K_{1}}{\left[\mathrm{H}^{+}\right]}+\frac{K_{1} K_{2}}{\left[\mathrm{H}^{+}\right]^{2}}+\frac{K_{1} K_{2} K_{3}}{\left[\mathrm{H}^{+}\right]^{3}}}{1+\frac{K_{1}}{\left[\mathrm{H}^{+}\right]}+\frac{K_{1} K_{2}}{\left[\mathrm{H}^{+}\right]^{2}}+\frac{K_{1} K_{2} K_{3}}{\left[\mathrm{H}^{+}\right]^{3}}}
$$

If the numerator is called $N$,

$$
\alpha(1-\alpha)=\frac{N}{(1+N)^{2}}=\frac{\left[\mathrm{H}_{3} \mathrm{PO}_{4}\right]}{[\mathrm{P}]} \times \frac{\left[\mathrm{H}_{2} \mathrm{PO}_{4}^{-}\right]+\left[\mathrm{HPO}_{4}^{2-}\right]+\left[\mathrm{PO}_{4}^{3-}\right]}{[\mathrm{P}]}
$$

where $[\mathrm{P}]=\left[\mathrm{H}_{3} \mathrm{PO}_{4}\right]+\left[\mathrm{H}_{2} \mathrm{PO}_{4}^{-}\right]+\left[\mathrm{HPO}_{4}^{2-}\right]+\left[\mathrm{PO}_{4}^{3-}\right]$.

If a 'chemical potential of phosphate anions in solution' is defined as

$$
\mu_{\Sigma \text { anions }}=\mu_{\Sigma \text { anions }}^{0}+R T \ln [\Sigma \text { anions }] \text {, }
$$

and it is assumed that the phosphate adsorbed at any $\mathrm{pH}_{2} \mathrm{P}_{\mathrm{a}}$, is determined by the chemical potentials of species in solution according to the equation

$$
\mathrm{P}_{\mathrm{a}}=C_{1}\left(\mu_{\mathrm{H}_{3} \mathrm{PO}_{4}}+\mu_{\Sigma \text { anions }}\right)
$$

then $P_{a}$ can be related to the logarithm of expression (3), since

$\ln \alpha(1-\alpha)=$

$$
\begin{aligned}
& =\ln \left[\mathrm{H}_{3} \mathrm{PO}_{4}\right]+\ln \left(\left[\mathrm{H}_{2} \mathrm{PO}_{4}^{-}\right]+\left[\mathrm{HPO}_{4}^{2-}\right]+\left[\mathrm{PO}_{4}^{3-}\right]\right)-2 \ln [\mathrm{P}] \\
& =\ln \left[\mathrm{H}_{3} \mathrm{PO}_{4}\right]+\ln [\Sigma \text { anions }]-2 \ln [\mathrm{P}] .
\end{aligned}
$$

And, multiplying by $R T$,

$$
\begin{aligned}
R T & \ln \alpha(1-\alpha) \\
= & \mu_{\mathrm{H}_{3} \mathrm{PO}_{4}}+\mu_{\Sigma \text { anions }}-\mu_{\mathrm{H}_{3} \mathrm{PO}_{4}}^{0}-\mu_{\Sigma}^{0} \text { anions }-2 R T \ln [\mathrm{P}] \\
= & \mu_{\mathrm{H}_{3} \mathrm{PO}_{4}}+\mu_{\Sigma \text { anions }}-\mu_{\text {total }}^{0}
\end{aligned}
$$

where

$$
\mu_{\text {total }}^{0}=\mu_{\mathrm{H}_{3} \mathrm{PO}_{4}}^{0}+\mu_{\Sigma \text { anions }}^{0}+2 R T \ln [\mathrm{P}] .
$$

If the total $\mathrm{P}$ concentration in solution is constant and high enough such that $\mathrm{P}_{\mathrm{a}}=x_{\mathrm{m}}$ (the maximum adsorption at a given $\mathrm{pH}$ ), equation (4) changes to

$$
x_{\mathrm{m}}=C_{1}\left(\mu_{\mathrm{H}_{3} \mathrm{PO}_{4}}+\mu_{\Sigma \text { anions }}\right)
$$

where $C_{1}$ is a constant whose meaning will be discussed later. 

(6),

Substituting the value of $\mu_{\mathrm{H}_{3} \mathrm{PO}_{4}}+\mu_{\Sigma \text { anions }}$ taken from equation

$$
x_{\mathrm{m}}=\left[R T \ln \alpha(1-\alpha)+\mu_{\mathrm{tota1}}^{0}\right] C_{1}=C_{2} \log \alpha(1-\alpha)+C_{3}
$$

where $\alpha(1-\alpha)$ is a function of $\left[\mathrm{H}^{+}\right], C_{2}=2.303 R T C_{1}$, and $C_{3}=\mu_{\text {tot a1 }}^{0} \cdot C_{1}$. Plotting experimental $x_{\mathrm{m}}$ values against $\log \alpha(1-\alpha)$ calculated for the corresponding $\mathrm{pH}$ values, a straight line should be obtained, whose slope should be $C_{2}$ and the intercept $C_{3}$.

\section{Tests of hypothesis}

Fig. 2 shows one typical relationship between $x_{\mathrm{m}}$ and $\log \alpha(1-\alpha)$, again using the results for goethite as an example. The linear correlation coefficients for all the oxides studied are shown in Table 1, which also shows the values of $C_{1}$ and $\mu_{\text {total }}^{0}$ calculated from the slopes and intercepts according to equation (8).

Equation (8) has also been applied to $x_{\mathrm{m}}$ read from the phosphate adsorption envelopes for three synthetic goethites given by Hingston et al. $(1967,1968,1971)$. As an example, Fig. 3 shows the relationship between $x_{x n}$ and $\log \alpha(1-\alpha)$ for one of them (Hingston et al., 1968). Calculated constants and linear correlation coefficients are given in Table 2.

From equation (8), and with constants given in Table 1, theoretical envelopes have been calculated for each oxide. The curve for goethite is shown in Fig. 1 (dashed line). The envelopes calculated were in close agreement with the experimental points, and all of them showed a change in the slope at a $\mathrm{pH}$ value close to 7.

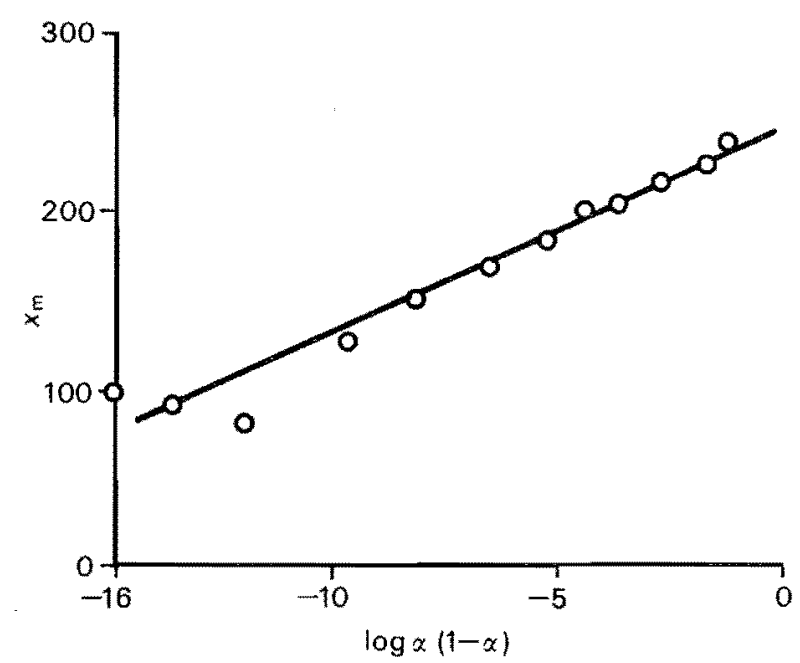

FIG. 2. Typical relationship (goethite) between experimental $x_{\mathbf{m}}$ and $\log \alpha(1-\alpha)$ calculated for each $\mathrm{pH}$ value using equation (3). 
TABLE 1

Linear correlation coefficients and constants calculated from equation (8) for the oxides studied here

\begin{tabular}{llll}
\hline Oxide & \multicolumn{1}{c}{$\mathrm{r}$} & \multicolumn{1}{c}{$\mathrm{C}_{1}$} & $\mu_{\text {total }}^{0}$ \\
\hline Gibbsite & $0.9467 * * *$ & $4.99 \times 10^{-3}$ & 13,986 \\
Boehmite & $0.8145^{*}$ & $2.94 \times 10^{-4}$ & 16,562 \\
Corundum & $0.9213^{* * *}$ & $1.31 \times 10^{-3}$ & 21,508 \\
Goethite & $0.9786^{* * *}$ & $8.38 \times 10^{-3}$ & 29,269 \\
Lepidocrocite & $0.9913^{* * *}$ & $1.66 \times 10^{-2}$ & 18,294 \\
Hematite I & $0.8604^{* *}$ & $1.65 \times 10^{-4}$ & 30,652 \\
Hematite II & $0.9573^{*} *$ & $2.80 \times 10^{-3}$ & 18,669 \\
Anatase & $0.9442 * * *$ & $5.07 \times 10^{-3}$ & 11,055 \\
Pyrolusite & $0.9736^{* * *}$ & $1.90 \times 10^{-4}$ & 20,234 \\
\hline
\end{tabular}

From Figs 1, 2, and 3, it can be stated that the assumptions made to deduce equation (8) agree with experimental results, which means that chemical potentials in solution of the three phosphate ions considered together as one component, and of undissociated phosphoric acid as another, determine the amount of phosphate adsorbed. The proportionality constant $C_{1}$ includes the influence of chemical affinity of the metal and surface area effects.

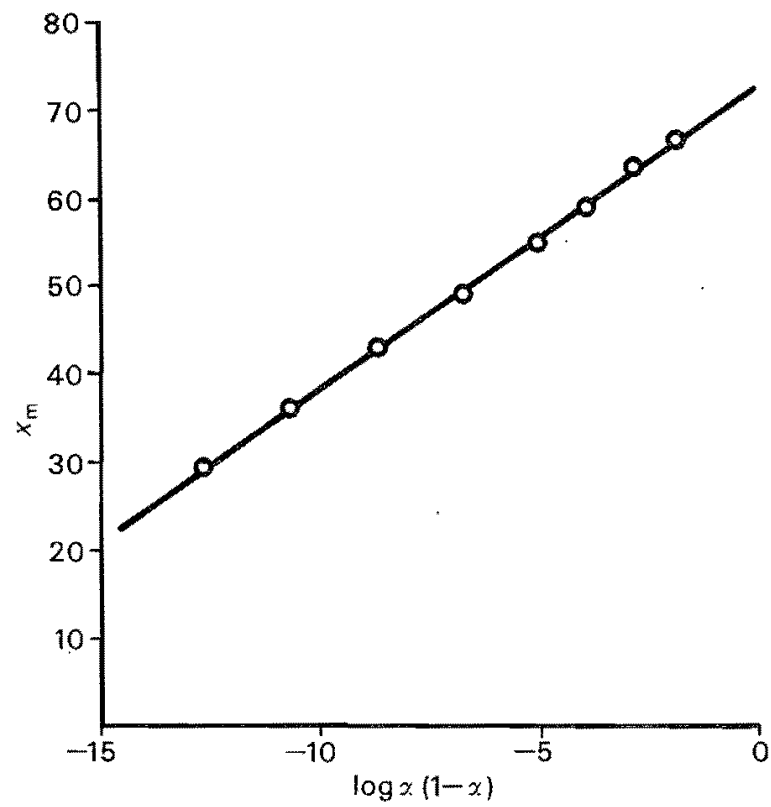

FIG. 3. Relationship between $x_{\mathrm{m}}$ given by Hingston et al. (1968) for goethite and $\log \alpha(1-\alpha)$ calculated for the corresponding $\mathrm{pH}$ values using equation (3). 
F. CABRERA, L. MADRID, AND P. DE ARAMBARRI

\section{TABLE 2}

Linear correlation coefficients and constants calculated from equation (8) for three goethites of Hingston et al. $(1967,1968,1971)$

\begin{tabular}{lccc}
\hline Reference & \multicolumn{1}{c}{$\mathrm{C}$} & $\mathrm{C}_{1}$ & $\mu_{\text {total }}^{0}$ \\
\hline 1967 & $0.9940^{* * *}$ & $3.40 \times 10^{-3}$ & 27,671 \\
1968 & $0.9993^{*} * *$ & $2.58 \times 10^{-3}$ & 28,374 \\
1971 & $0.9978 * * *$ & $5.07 \times 10^{-3}$ & 31,325 \\
\hline
\end{tabular}

- - - Aluminium oxides

-.-.-- Iron oxides

O Gibbsite

- Goethite A (Hingston et al., 1971)

$\otimes$ Corundum $\nabla$ Goethite (Hingston et al., 1968)

- Boehmite 口 Hematite II

$\checkmark$ Lepidocrocite $\oplus$ Hematite 1

$\triangle$ Goethite

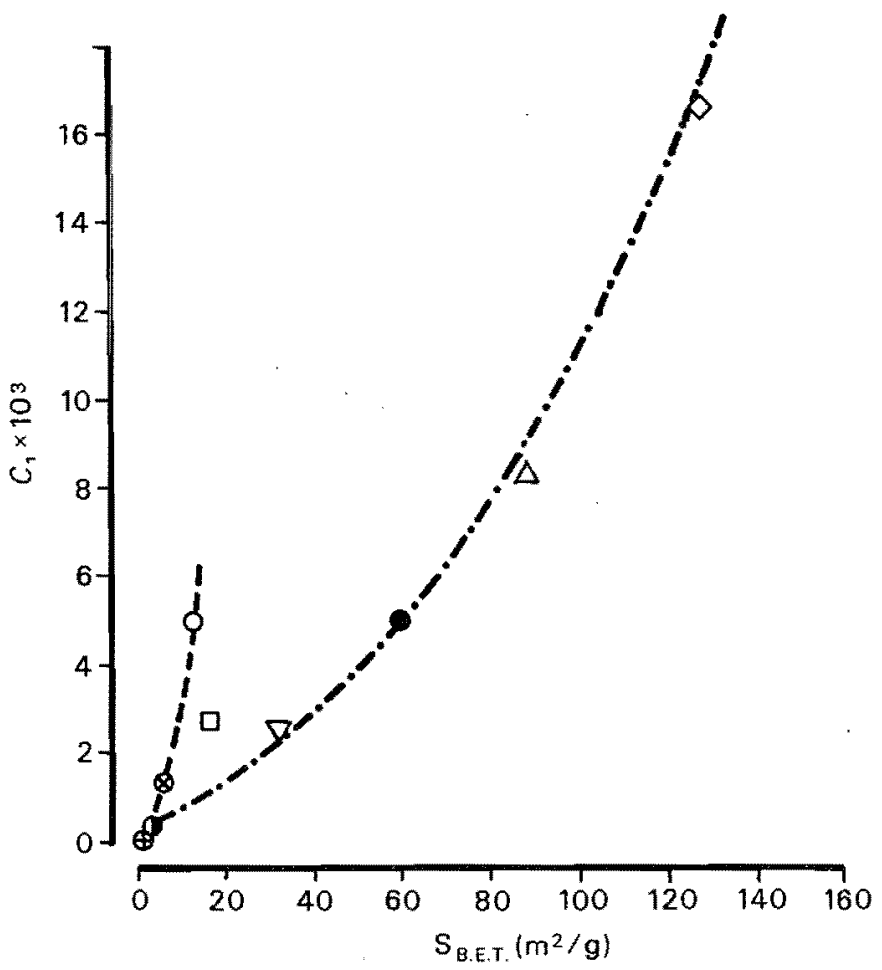

FIG. 4. Relationships between $C_{1}$ and specific surface area for aluminium and iron oxides, 
Some deviations from linearity of the plots of $\log \alpha(1-\alpha)$ against $x_{m}$ at very low or very high $\mathrm{pH}$ values could be due to influences of very high positive or negative surface charge, that are not considered if $C_{1}$ is supposed to be constant over the entire $\mathrm{pH}$ range.

Fig. 4 shows the relationship between $C_{1}$ and the specific surface area for aluminium and iron oxides. Two goethites from Hingston $e t$ al. $(1968,1971)$ have been included. It is shown that $C_{1}$ is greater for aluminium than for iron oxides for a given value of the specific surface area. This conclusion agrees with results of other authors (Gastuche $e t$ al., 1963; Taylor et al., 1964; Arambarri and Madrid, 1971), that aluminium oxides are more reactive than iron oxides of similar specific surface areas.

\section{Acknowledgement}

Authors are grateful for the technical help they received from Miss M. F. Osta, Dr. J. Cornejo, and Mr. J. Muñoz.

\section{REFERENCES}

ARAMBARRI, P., and MADRID, L. 1971. Reacción de óxidos de hierro y aluminio con fosfato dicálcico dihidrato. An. Edaf. Agrob. 30, 1083-94.

BOWDEN, J. W., BOLLAND, M. D. A., POSNER, A. M., and QUIRK, J. P. 1973. Generalized model for anion and cation adsorption at oxide surfaces. Nature, Lond. (Phys. Sci.) 245, $81-3$.

BRAUER, G. 1958. "Química Inorgánica Preparativa". Reverté. Barcelona.

GASTUCHE, M. C., FRIPIAT, J. J., and SOKOLSKI, S. 1963. Fixation du phosphore par les hydroxydes de fer et d'aluminium amorphes et cristallisés. Pedologie 13, $155-80$.

HERRMANN, M., and BOEHM, M. P. 1969. Uber die Chemie der Oberfläche des Titandioxids. II. Saure Hydroxygruppen auf der Oberfläche. Z. Anor. Allgem. Chem. 336, 73.

HINGSTON, F.J., ATKINSON, R. J, POSNER, A.M., and QUIRK, J. P. 1967. Specific adsorption of anions. Nature, Lond. 215, 1459-61. Soil Sci. $1,669-78$.

968. Specific adsorption of anions on goethite. Trans. 9th int. Cong.

POSNER, A. M., and QUIRK, J. P. 1970. Anion binding at oxide surfaces. The adsorption envelope. Search 1, 324-7.

Disc. Faraday Soc. no. $52,334-42$.

1972. Anion adsorption by goethite and gibbsite. I. The role of the proton in determining adsorption envelopes. J. Soil Sci. 23, 177-92.

MULJADI, D., POSNER, A. M., and QUIRK, J.P. 1966. The mechanism of phosphate adsorption by kaolinite, gibbsite and pseudoboehmite. J. Soil Sci. 17, 212-47.

MURPHY, J. and RILEY, J. P. 1962. A modified single solution method for the determination of phosphate in natural waters. Analy tica chim. Acta 27, 31-6.

OBIHARA, C. C. H. 1969. Interactions between soluble silica and phosphate in soils. Ph. D. thesis, Univ. Reading.

TAYLOR, A. W., GURNEY, E. L., and MORENO, E. C. 1964. Precipitation of phosphate from calcium phosphate solutions by iron oxide and aluminum hydroxide, Proc. Soil Sci. Soc. Am. $28,48-52$. 